\title{
Der Telegraphenbetrieb
}

in Kabelleitungen. 

Der

\section{Telegraphenbetrieb}

\section{in Kabelleitungen}

unter besonderer Berücksichtigung der in der

Reichs-Telegraphenverwaltung bestehenden Verhältnisse

ron

\section{E. Müller}

Telegraphen-Ingenieur im Reichs-Postamt.

\section{Zweite Auflage.}

Mit 26 in den Text gedruckten Figuren.

Berlin.

Julius Springer.
1891.

München.

R. Oldenbourg. 
DRUCK VON H. S. HERMANN IN BERLIN. 